\title{
Patterning of silicon by indentation and chemical etching
}

\author{
R. Rao, ${ }^{a)}$ J. E. Bradby, and J. S. Williams \\ Department of Electronic Materials Engineering, Research School of Physical Sciences and Engineering, \\ The Australian National University, Canberra ACT 0200, Australia
}

(Received 8 July 2007; accepted 13 August 2007; published online 20 September 2007)

\begin{abstract}
An array of features on $\mathrm{Si}(100)$ is fabricated by a new maskless pattering process involving a combination of indentation and anisotropic wet chemical etching. Indentation is carried out in order to induce transformation to the high-pressure phases, Si III and Si XII, before etching in a $\mathrm{KOH}$ solution. The pressure-induced phases are found to be highly resistant to etching in the $\mathrm{KOH}$ solution, with an etch rate more than an order of magnitude slower than that of $\mathrm{Si}$ (100). The possibility of exploiting this mechanism for a maskless nanoscale patterning process in Si using indentation is discussed. (C) 2007 American Institute of Physics. [DOI: 10.1063/1.2779111]
\end{abstract}

Silicon is widely used in the fabrication of integrated circuits, microelectromechanical systems, and optoelectronic devices. It has been known for some time that crystalline silicon $(c-\mathrm{Si})$ undergoes a series of pressure-induced phase transformations during indentation. ${ }^{1-6}$ Diamond-cubic $c$-Si (so-called Si I) transforms to a metallic $\beta$-Sn phase (Si II) during indentation loading at a pressure of $\sim 11 \mathrm{GPa}^{3}$ Upon pressure release, $\mathrm{Si}$ II undergoes further phase transformation as it is not stable at a pressure below $\sim 8 \mathrm{GPa}^{2}$. The final phase structure has been previously observed to be either amorphous silicon $(a-\mathrm{Si})$ (formed during fast unloading rates) or a mixture of the high-pressure polycrystalline phases (HPPs) Si XII and Si III (favored by slow unloading). ${ }^{4-6}$ Interestingly, the electrical and mechanical properties of the HPPs differ considerably to those of $a$-Si or $c$-Si, (Ref. 7) opening up the possibility of utilizing these phases to develop different types of micro-/ nanosemiconductor devices. However, little is known about the nature of the HPPs and how they respond to basic semiconductor processing. The objective of this work was to study the etching behavior of indentation-induced structures in $c$-Si. It has been found that good etch selectivity occurs between the indentation-induced HPPs and the surrounding $c$-Si, raising the prospect of using indentation for maskless patterning of Si.

Currently, patterning of silicon-based structures and devices employs a number of masking and etching steps. Several anisotropic etchants have been used for etching silicon surfaces, and $\mathrm{KOH}$ is a popular etchant as it produces a uniform, bright surface and has high etch selectivity with $\mathrm{SiO}_{2}$ which is usually used as a mask during the etching process. ${ }^{8-13}$ Thus, $\mathrm{KOH}$ was selected as the etchant for this study. The effects of the etching process on the structure of HPPs, the surface topography, and the roughness of the surrounding $c$-Si are examined by atomic force microscopy (AFM), Raman microspectroscopy, and cross-section transmission electron microscopy (XTEM).

Indentations were made using the Ultra-Micro Indentation System-2000 with a spherical indenter of $\sim 5 \mu \mathrm{m}$ radius at loads of up to $80 \mathrm{mN}$ in Czochralski-grown $p$-type $\mathrm{Si}$ (100) wafers with a resistivity of $10-20 \Omega \mathrm{cm}$. A slow unloading rate of $\sim 2 \mathrm{mN} / \mathrm{s}$ was used in order to favor the

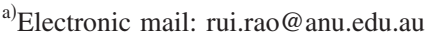

formation of the HPPs. After indentation, a chemical etch was performed using $\mathrm{KOH}$ solution of $30 \mathrm{wt} \%$ at $80^{\circ} \mathrm{C}$ for $1 \mathrm{~min}$. The residual indent impressions were imaged by AFM before and after etching. Additionally, the indents were characterized before and after etching by Raman microspectroscopy using a Reinshaw 2000, of which the $632.8 \mathrm{~nm}$ excitation line of a helium-neon laser was focused to a spot of $\sim 1.0 \mu \mathrm{m}$ radius. Selected indents were also characterized using XTEM, for which the samples were prepared using a dual-beam focused ion beam system and the "pluck-out" method as described elsewhere. ${ }^{14}$

An AFM image of four indents containing HPPs before etching is shown in Fig. 1(a). The indents are spaced $10 \mu \mathrm{m}$ apart, are $\sim 2 \mu \mathrm{m}$ wide, and have a residual depth of $\sim 100 \mathrm{~nm}$. The depths of the residual indent impressions are consistent with the final penetration depth given by indentation data (not shown). ${ }^{5}$ Figure 1(b) shows an AFM image of four indents after etching. It is clearly observed that the surrounding $c$-Si substrate has been etched away from around the indents resulting in a moundlike structure. This indicates that the undeformed $\mathrm{Si}(100)$ surface is etched at a much faster rate compared to the indents containing HPPs. The

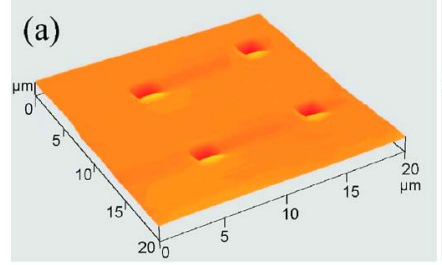

(b)

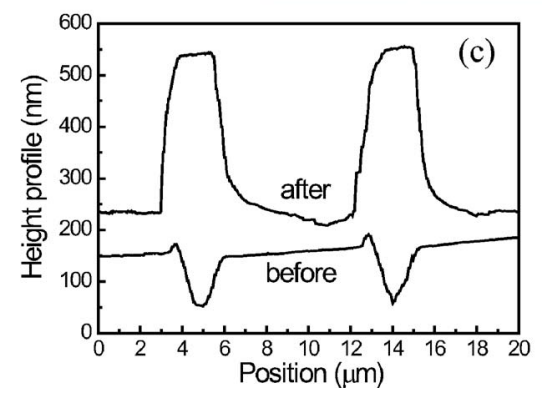

FIG. 1. (Color online) (a) AFM image of $2 \times 2$ arrays of HPP on Si (100) surface before etching. (b) AFM image of $2 \times 2$ arrays of HPP on Si (100) surface after etching. (c) Section profile of HPP indents before and after etching. 

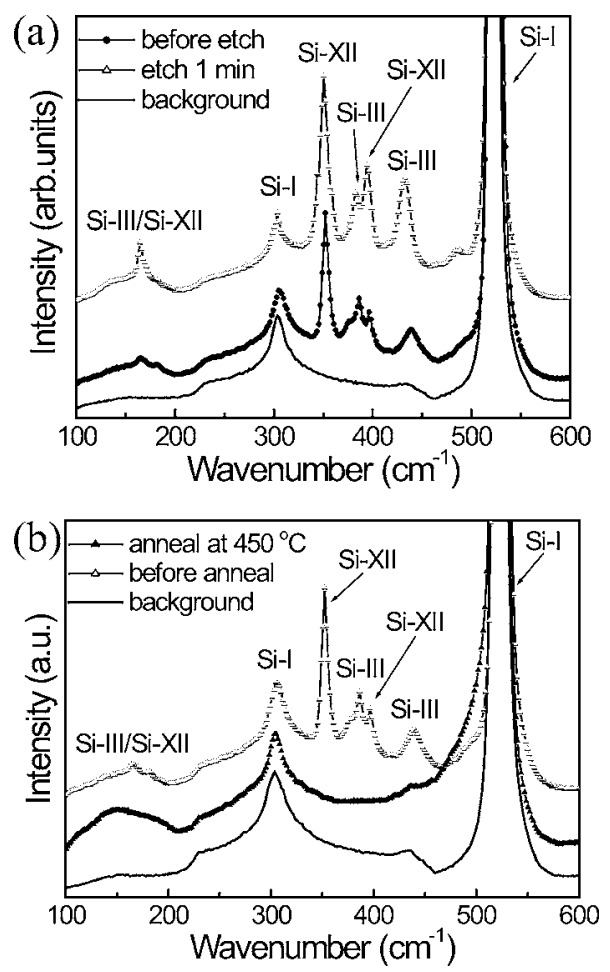

FIG. 2. (a) Raman spectra of indents before and after etching. (b) Raman spectra of indents before and after annealing.

height of the mounds was measured to be $\sim 500 \mathrm{~nm}$ using AFM [see Fig. 1(c)]. Together with the residual indent depth of $100 \mathrm{~nm}$, approximately $600 \mathrm{~nm}$ of Si (100) has been removed giving an etch rate for $\mathrm{Si}$ (100) of $600 \mathrm{~nm} \mathrm{~min}^{-1}$, consistent with previously reported etch rates for this material. ${ }^{13}$ The $2 \mu \mathrm{m}$ width of the mound is similar to the initial size of the indent prior to etching, indicating that the lateral etching of HPP is negligible.

Figure 1(b) clearly demonstrates that the etch rate of HPPs is considerably slower than that of the surrounding $c$-Si. However, in order to quantify the rate of etching of the HPPs, a line of overlapping large indents ( $7 \mu \mathrm{m}$ radius) was created and etched for longer periods of time. This revealed an approximate etch rate for the polycrystalline Si III/Si XII mixture of $\sim 50 \mathrm{~nm} \mathrm{~min}{ }^{-1}$.

The indents made by the $\sim 5 \mu \mathrm{m}$ radius tip were additionally characterized by Raman microspectroscopy both before and after etching, and the results are shown in Fig. 2(a). Pristine diamond-cubic Si I has Raman bands at 300 and $521 \mathrm{~cm}^{-1}$. ${ }^{5,13}$ The additional multiple Raman bands at 161 , 350382,394 , and $430 \mathrm{~cm}^{-1}$ which can be clearly seen in this figure indicate the presence of the HPPs Si III and Si XII. ${ }^{5,13}$ Clearly, the phase structure of the residual indents is retained following the $1 \mathrm{~min}$ etching process. Moreover, the HPP bands appear more clearly defined after etching, indicating that the measured relative intensity of HPPs is greater than that of Si I. This is most likely to be caused by the removal of the surrounding Si I during etching, leaving a larger area of HPP exposed. This figure also suggests that the etch rate of the two phases (Si III and Si XII) might differ slightly as the ratio of the Raman bands (at $430-350 \mathrm{~cm}^{-1}$ ) changes from 0.4 before etching to 0.7 after etching. However, as Si III and Si XII are nearly always detected together, ${ }^{5,15}$ we only consider the etch rate of the mixture of these phases in

this letter.
Downloaded 29 Jan 2008 to 150.203.180.149. Redistribution subject to AIP license or copyright; see http://apl.aip.org/apl/copyright.jsp

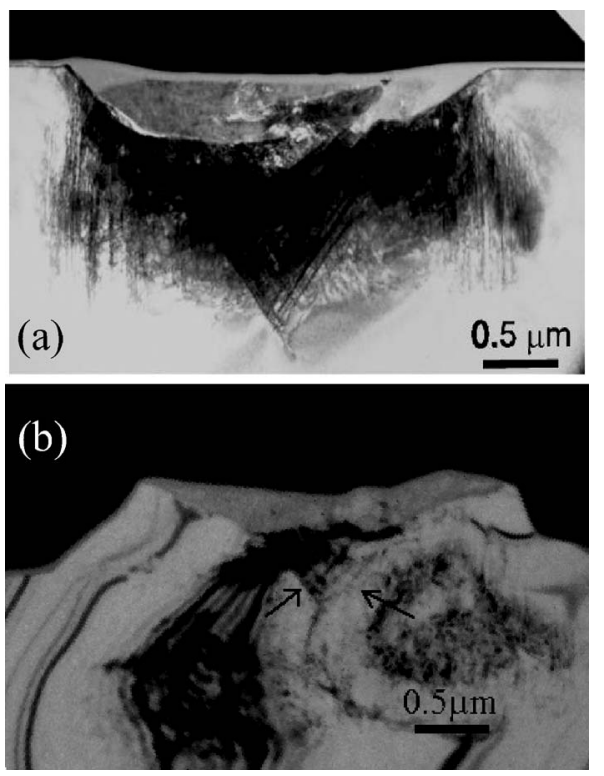

FIG. 3. XTEM images of HPP on Si (100) surface before (shown as an inset) and after etching.

The structure of the indents both before and after etching was further examined by XTEM, as shown in Figs. 3(a) and 3 (b), respectively. The bright-field (BF) image of the residual indent [Fig. 3(a)] before etching shows a region containing HPPs extending approximately $500 \mathrm{~nm}$ down from the surface with a region of $a-S i$ at each edge. Such amorphous regions at the periphery of spherical indents have been previously reported as forming during the localized fast pressure release that occurs in Si II at the edge of the contact of the indenter with the surface during the pop-in event. ${ }^{7}$ Figure 3(b) shows a BF XTEM image of an indent after etching. The presence of HPPs was confirmed by selected areadiffraction patterns of the deformed region. The size of the residual mound agrees with that observed from the AFM section profile, as shown in Fig. 1(c). Moreover, by comparing the XTEM image with that before etching almost the same size $(\sim 2 \mu \mathrm{m})$ of HPP indents before and after etching suggests that there is virtually no lateral loss of HPPs during etching. In addition, the pileup $a$-Si region, which shown in Fig. 1(c), before etching completely disappeared after $1 \mathrm{~min}$ etching. The missing $a$-Si can also be confirmed from XTEM image after etching. The reason for that is due to the very slow etch rate of $a-\mathrm{Si}$ which is similar to that of HPP.

It is further interesting to consider the final shape of the etched HPP structure. The edges of the HPP [see arrows in Fig. 3(b)] can be seen to form at an angle of $54^{\circ}$ to the surface, indicating that this is the $\{111\}$ planes. This was not etched due to well-known etching selectivity of the different crystallographic directions of $c$-Si in $\mathrm{KOH}$ etchant. ${ }^{13}$ When the surface of the $\{100\}$ planes drops below the HPPs (as shown), no significant lateral etching occurred as the encountered exposed $\{111\}$ planes has an etching rate of $5 \mathrm{~nm} \mathrm{~min}{ }^{-1}$ under the conditions studied here, ${ }^{16}$ significantly slower than the $\{100\}$ planes. The difference of etching rate between these two sets of planes in $c$-Si has been widely used to micromachine and microelectromechanical devices and texture solar cells. ${ }^{8,17}$ The AFM and XTEM images also show that the surface of $\mathrm{Si}(100)$ is smooth which results from a uniform etching rate on the (100) sample surface. 

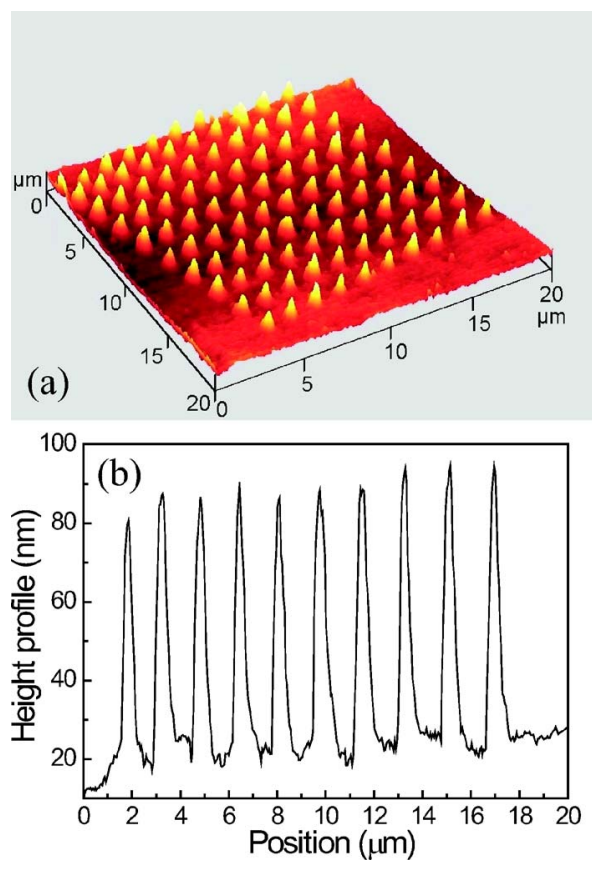

FIG. 4. (Color online) (a) AFM image of $10 \times 10$ arrays of HPP on Si (100) surface after etching. (b) Section profile of ten HPP indents after etching.

A further observation involves the annealing of the HPPs. It has been previously reported that Si III and Si XII transform back to a polycrystalline Si I structure when annealed at temperature as low as $175^{\circ} \mathrm{C}$ for 120 mins. ${ }^{18,19} \mathrm{In}$ this current study, the indents containing the HPP were annealed for $30 \mathrm{~min}$ at a temperature of $\sim 450{ }^{\circ} \mathrm{C}$ in an argon atmosphere to transform the HPP structures to polycrystalline Si I. This transformation was confirmed with Raman microspectroscopy, as shown in Fig. 2(b). Subsequent etching of the annealed indents with the $\mathrm{KOH}$ solution provided an effective method to easily remove polycrystalline $\mathrm{Si}$ I and expose underlying undamaged $\mathrm{Si}$ I within the indent mound. Thus, the HPP mask can be readily removed by this procedure.

Finally, the repeatability and scalability of the indentation/etching process are demonstrated. Figure 4 shows an AFM image of a $10 \times 10$ array with indents $\sim 500 \mathrm{~nm}$ in diameter and a height of $\sim 60 \mathrm{~nm}$. This array was formed using a TriboIndenter (Hysitron Inc., USA) with a Berkovich tip at loads of up to $5000 \mu \mathrm{N}$ and etched with the same $\mathrm{KOH}$ process as outlined above for $30 \mathrm{~s}$. This image demonstrates that it is possible to produce a large array of nanoscale features on a $\mathrm{Si}(100)$ surface using this maskless method, where indentation locally produces HPPs which provide etch selectivity.

The results of this study clearly show that the polycrystalline high-pressure phases Si III/Si XII formed via indentation have more than an order of magnitude slower etch rate in $\mathrm{KOH}$ than in Si I. These phases are known to be quasistable ${ }^{19}$ and undergo a further transformation to the energetically more stable (lower-free energy) Si I phase on annealing. ${ }^{18}$ This behavior and the ability to easily remove polycrystalline Si I with subsequent etching allow the HPP mask to be readily removed to expose the original surface crystalline Si I within the remnant indent-induces mound. The fact that the HPPs etch around 15 times slower than $\mathrm{Si}$ $\{100\}$ causes mounds to form on the silicon surface and the exposure of $\mathrm{Si}\{111\}$ planes on mound edges that etch at around 100 times slower than $\mathrm{Si}(100)$ for $\mathrm{KOH}$ etching. ${ }^{8}$ These two outcomes result little undercutting of HPP regions during etching and in the generation of mounds on the surface with a diameter that matches the original size of HPP regions. It is difficult to comment further on the nature of the HPP etching mechanisms. Indeed, despite the fact that etching of $\mathrm{Si}$ in aqueous $\mathrm{KOH}$ is a well used process in a number of industries, there is no clear understanding of the selective mechanisms of etching. ${ }^{8,20}$

In summary, we have demonstrated that a combination of indentation and $\mathrm{KOH}$ etching can readily produce arrays of features on $c$-Si without the use of a masking process. The $\mathrm{KOH}$ solution showed good etching selectivity between $\mathrm{Si}$ $\{100\}$ and indentation-induced HPPs, with the HPPs remaining intact during the etching process. The HPP mask can be readily removed by annealing and subsequent etching opening up the prospects for using this maskless patterning process for fabrication of various structures and devices.

The authors would like to acknowledge the Australian Research Council and the WRiota Pty Ltd. for funding.

${ }^{1}$ D. R. Clarke, M. C. Kroll, P. D. Kirchner, R. F. Cook, and B. J. Hockey, Phys. Rev. Lett. 60, 2156 (1988).

${ }^{2}$ J. Crain, G. J. Ackland, J. R. Maclean, R. O. Piltz, P. D. Hatton, and G. S. Pawley, Phys. Rev. B 50, 13043 (1994).

${ }^{3}$ M. Imai, T. Mitamura, K. Yaoita, and K. Tsuji, High Press. Res. 15, 167 (1996).

${ }^{4}$ J. E. Bradby, J. S. Williams, and J. Wong-Leung, Appl. Phys. Lett. 77, 3749 (2000).

${ }^{5}$ J. E. Bradby, J. S. Williams, and J. Wong-Leung, J. Mater. Res. 16, 1500 (2001).

${ }^{6}$ I. Zarudi, L. C. Zhang, W. C. D. Cheong, and T. X. Yu, Acta Mater. 53, 4795 (2005).

${ }^{7}$ J. E. Bradby, J. S. Williams, and M. V. Swain, Phys. Rev. B 67, 085205 (2003).

${ }^{8}$ H. Seidel, L. Csepregi, A. Heuberger, and H. Baumgartel, J. Electrochem. Soc. 137, 3612 (1990).

${ }^{9}$ I. Zubel and I. Barycka, Sens. Actuators, A 70, 250 (1998).

${ }^{10}$ K. Sato, M. Shikida, T. Yamashiro, M. Tsunekawa, and S. Ito, Sens. Actuators, A 73, 122 (1999).

${ }^{11}$ I. Zubel, Sens. Actuators, A 70, 260 (1998).

${ }^{12}$ D. Resnik, D. Vrtacnik, U. Aljancic, M. Mozek, and S. Amon, Microelectron. J. 34, 591 (2003).

${ }^{13}$ I. Zubel and M. Kramkowska, Sens. Actuators, A 93, 138 (2001).

${ }^{14}$ R. M. Langford and A. K. Petford-Long, J. Vac. Sci. Technol. A 19, 2186 (2001).

${ }^{15}$ S. Ruffell, J. E. Bradby, and J. S. Williams, Appl. Phys. Lett. 89, 091919 (2006).

${ }^{16}$ K. Sato, M. Shikida, Y. Matsushima, T. Yamashiro, K. Asaumi, Y. Iriye, and M. Yamamoto, Sens. Actuators, A 64, 87 (1998).

${ }^{17}$ P. Campbell and M. A. Green, Sol. Energy Mater. Sol. Cells 65, 369 (2001).

${ }^{18}$ S. Ruffell, J. E. Bradby, and J. S. Williams, Appl. Phys. Lett. 90, 131901 (2007).

${ }^{19}$ D. Ge, V. Domnich, and Y. Gogoshi, J. Appl. Phys. 95, 2725 (2004).

${ }^{20} \mathrm{M}$. Elwenspoek, U. Lindberg, H. Kok, and L. Smith, Proceedings of the IEEE Workshop on Micro Electro Mechanical System, Oiso, Japan (IEEE, New York, 1994), pp. 223-228. 